ARTICLE HISTORY: Received: December 4, 2021 Accepted: January 28, 2022 Published: February 4, 2022

\title{
IN SEARCH OF GOOD PRACTICES IN STRATEGIC HUMAN RESOURCE MANAGEMENT IN TIMES OF CRISIS
}

\author{
Borislava Borislavova Galabova \\ Boryana Yordanova Trifonova \\ Vessela Emilova Petrova \\ Department of Economics and Management \\ University of Mining and Geology "St. Ivan Rilski”, Bulgaria
}

\begin{abstract}
The article presents the results of a study of the new practices in strategic human resource management in the raw materials industry. An analysis of the approaches and models for adapting to the business challenges posed by the COVID pandemic is made. Conclusions have been drawn on the results achieved and the applicability of the different approaches to the stabilisation, business sustainability, efficiency, and normal running of the production process. The analyzed practices are applicable and useful in other industrial enterprises, which must adapt the work process to the new requirements and real opportunities for the work process.
\end{abstract}

Keywords: strategic management, human resource management, crisis management, industry, enterprise

\section{Introduction}

In today's society, crisis management is an integral part of strategic enterprise management, as crises of various nature occur all the time. When they occur, they affect every enterprise and its structures, although they show different manifestations, scope and forms of affect. The global pandemic that broke out in late 2019 and early 2020 brought recession and economic crisis in its wake and impacted enterprises in the industrial sector. The industry was severely affected by the pandemic and the anti-epidemic measures as the production process and supply chains were severely hampered, with demand for certain groups of goods also restricted. The crisis had a negative impact on the state, prospects, and development trends of the extractive industries. The study focuses on the crisis management measures implemented by companies in the subsector over the past two years and their results. The study's focus is on the practices and measures used in raw materials enterprises to manage human resource strategically during times of crisis. They strive to avoid resorting to redundancy, to preserve the health and lives of employees, and to ensure a safe and healthy environment by reorganizing and restructuring production and administrative activities. A survey of business representatives explored a range of examples in search of a balanced approach to deal with the pandemic and the crisis it has caused. Effective, long-term solidarity measures are sought for all stakeholders, including workers, employees, and managers. On the basis of the survey, generalizations are made about good practices in strategic human resource management.

The impact of the COVID crisis on the activity of the industrial enterprises

The pandemic highlighted the fragility of the foundations of the 21 st century economy, which is characterized by great technological advances and remarkable globalization centered around globally connected production and supply chains seeking to maximize profitability. Measures related to the introduction of full or partial lockdowns in different geographic regions have led to widespread economic collapse with significant consequences for output and employment and a strong impact on all areas of economic activity due to the sharp reduction in consumption [12].

The functioning of the enterprise is a continuous process of adaptation to environmental conditions to maintain a balance between the internal (inherent) characteristics of the enterprise as a business entity and the characteristics of the dynamically changing market [1, p. 89]. Maintaining this dynamic equilibrium is a difficult but important task because the loss of balance creates the risks of managerial, organizational, operational, and financial crises. Each crisis, depending on its nature, brings with it certain adverse influences. They are most often in several aspects at the same time: the economy, the social sphere and public life, security, political stability, ecology and the environment. It affects some more sharply than others, and several different aspects are affected simultaneously. Negative effects can accumulate and influence each other, achieving a synergistic effect.

By its very nature, a crisis is seen as a situation of high-intensity shocks and risks, for which a solution is usually sought to overcome it. Such a situation requires specific decisions to be made and actions to be taken, as well as events and measures to be planned, organized, and implemented. In economics and corporate governance, such a situation is particularly difficult because it affects all economic actors, changes market relations between them, causes imbalances, and leads to various consequences for the production process, investment, innovation, logistics, trade, marketing, and sales.

Every economic system operates in dynamic conditions. However, for its functioning to be successful, it is guided by a fundamental principle: the desire to maintain relative stability, balance, and resilience, which leads to the limitation of shocks and their effects. The economic system goes through different periods in the course of development, one of 
which is a crisis, and this is an inevitable part of the economic cycle. In crisis circumstances, a slowdown in economic activity accompanies the process of economic development at national, international, and global levels. In the economy, the crisis is exacerbating adverse economic trends and worsening the outlook.

By definition, an economic crisis is a negative phenomenon in which threats to economic life of various kinds arise en masse. The crisis is a sharp deterioration of the economic situation of a country, manifested by a significant decline in production, disruption of existing production links, bankruptcy of enterprises, increased unemployment, and, ultimately, a decline in the standard of living and the welfare of the population. The crisis is a complex phenomenon with different expressions. It shakes the foundations and affects the sustainability of the enterprise through the uncertainty of the environment in which it has to operate. It brings together purely technical, business, financial, social, and political factors that operate simultaneously [7, p. 5]. Generally, an economic crisis occurs when the economy moves out of its equilibrium state due to the impact of factors endogenous or exogenous to the economic system. This has implications for the management of any enterprise, necessitating inevitable changes in strategy and policy, especially as regards human resource management.

Crises, as a phenomenon, are different in nature and character, and also in the reasons for their occurrence. They are different in their scope, degree of spread, depth of impact, strength, and consequences. Respectively, the reactions of the state and business in response to one or another crisis may also not be the same, if the situation and the specifics of the crisis that has occurred or is under way are taken into account. The consequences of the economic crisis can be found in different directions. Some of these are a decline in production or overproduction, a fall in demand, a recession, a rise in unemployment, a decline in income, living standards, and social welfare, a fall in economic activity, and limited opportunities to invest and secure funding for innovation and reconstruction, modernization, and infrastructure projects.

Regardless of the consequences, crisis response and management necessarily go through concrete changes and steps to adapt to the situation from the perspective of the business actors themselves. Adaptation, in turn, often goes through innovation and innovative approaches because crises bring lasting changes and by this encourages them. They question the existing models and accumulated knowledge to which enterprises turn to find external support and new approaches to production and management.

As in modern society, crises occur frequently, their management is an integral part of strategic enterprise management. The longer the crisis lasts, the more the enterprise and its structures and processes will be affected. Effective crisis management therefore requires the enterprise to successfully navigate through the adverse situation and contain the shocks to limit losses and negative impacts on operations and business development. This often requires using non-traditional models and approaches and changing business models because, if ones are already in place, they are not always applicable in a crisis context.

In the economic literature, the crisis is seen as a deviation from the normal course of business development. It therefore requires an appropriate response and anti-crisis interventions to get the system back on track and to restore stability. In the event that normal course cannot be restored in the medium term, the objective is first and foremost to limit the negative effects of the crisis on the company's operations and results. Secondly, a model is sought to achieve stabilization in the longer term.

The global pandemic that broke out in late 2019 and early 2020 has led to a recession and an economic crisis. The economic crisis in which the world economy has fallen is described by analysts as the most serious and significant since the Great Depression of the 1930s. This crisis is very different from the "classic" crises we have witnessed, at least in the reason for its occurrence. It was preceded by an acute health and medical crisis, unprecedented in recent history, which forced the introduction of emergency measures, economic and social restrictions at national, European and international level. At the enterprise level, the current crisis has impacted and continues to impact in two main directions. First, the economic and financial difficulties that enterprises face in organizing and carrying out the activities for which capital is needed. Second, in the direction of exacerbating risks and holding back investment intentions until a more favorable time and predictable business environment occur. The crisis has led to economic uncertainty and instability and has aggravated certain risks to industrial activity, as the duration and severity of the pandemic cannot yet be predicted and estimated. This has contributed to increased uncertainty about the restrictions that the authorities would impose and an inability to plan on time the activities in accordance with future measures. This inability to plan puts industrial businesses in a complex and precarious position, as production processes are usually continuous in nature and involve regular sourcing, finance, active supplier relationships, and constant communication with internal and external markets.

The contraction in economic activity in the context of the sovereign crisis is associated with a significant decline in industrial production and a deterioration in the performance of industrial businesses. This trend led to a slowdown in the European economy and changed its direction. Therefore, one of the most important questions is what should be the behavior of the industrial sector in the crisis situation so as to achieve recovery and stabilization. Approaches and measures should be sought that have the potential to help reach the inversion point, after which economic recovery will begin.

In Bulgaria, the restrictive measures imposed have a shock effect on over 346 thousand enterprises and on over 3.2 million people employed in various activities [3, p. 1]. The industry sector was severely affected by the pandemic and the anti-epidemic measures, as the production process was severely hampered, supply chains were temporarily or 
permanently disrupted, and demand for certain groups of goods was reduced at the expense of others. In terms of supply, it has also been affected. Producers have had to overcome a number of difficulties to produce and market their products, to find the necessary resources for production, or to reach consumers safely and efficiently. In this regard, it was necessary to look for, select, and implement new models for the organization and management of the manufacturing process, as well as to restructure and impose new working models while changing short- and long-term goals. Indeed, the crisis has shown that the current business models need to be changed to fit the organizational strategy to deal with the crisis. Every company should develop a strategy to help it keep pace with market changes [14]. They need to be adapted to continue to work so that they can provide a relevant response to emerging issues in business practice.

The crisis had a negative impact on the state, prospects, and development trends of the raw materials industry. However, companies in the sub-sector are trying not to move towards redundancies but rather to reorganize and restructure their operations. The ambition is to continue to operate by taking the necessary measures to protect the health and safety of workers and employees, adapting the production and human resource management process to the new realities and continuing their investment program. The main problems that these industrial enterprises have faced since the beginning of 2020 are the risks of temporary and short-term disruptions to the production process, the difficulties in maintaining relationships with suppliers and contractors, supply chain disruptions, significant price dynamics, and the need to preserve the life and health of human resource. Economic activity and industrial production are declining. There has been a fall in exports and a shift in demand for the raw materials industry products due to a reduction in industrial activity. As a result, in 2020, according to the Bulgarian NSI, the sub-sector's output is expected to decrease by $3 \%$ on a year-to-year basis.

The logical business response to the situation would be to abandon planned investment intentions, refuse to plan and implement innovation and human resource development programs, make changes in the production process, optimize costs, and freeze modernization processes. However, the raw materials companies are pursuing a moderate policy and are not taking extreme measures and actions, focusing instead on measures to preserve their achievements and follow planned programs. As evidenced by this survey, the business response to the unforeseen and unexpected pandemic crisis is clear and justified. There is an attempt to adapt quickly and adequately while continuing to seek the most realistic and achievable solutions to deal with the situation and for further sustainable development, despite the crisis and the many unknowns it poses. The only thing that is fully known is that the current policies, strategies, methods, and practices should undergo changes in order to comply with the new requirements and realities. The mining business also continues its attempts to adapt to the current crisis environment. There are a number of examples of following a balanced approach to deal with the pandemic and the crisis it has caused, involving long-term and solidaritybased measures for all stakeholders, including workers, employees, and managers.

Because market conditions, consumer behavior, and attitudes have a direct impact on mining and metal production, shocks are difficult to avoid but can be effectively managed. In such conditions and with exacerbated risks to industrial business, it is difficult but imperative to make changes. There are two key issues to tackle the crisis: maintaining business resilience recovery and future development of industrial enterprises. The first one is whether managers recognize the crisis as an opportunity for beneficial change and whether they are prepared to make the changes that will overcome it. The second issue is whether they are ready and open to plan and implement such changes in practice. Changes have proven to be one of the tools to overcome the crisis and adjust to the "new normal", which will be a longterm trend.

The world economy has undergone a number of profound and meaningful changes in the last decade before the pandemic. They have also been reflected in theory and public discourse through the introduction of new concepts such as "new economy", "digital economy", "knowledge society", "information society" and "knowledge economy". These changes in direction have mixed effects, but they highlight the scope of action for businesses. A transformation of business and governance models towards opening up and flexibility started before the pandemic, but the crisis accelerated its course. Businesses have begun to recognize the opportunity to tap into the potential of information and communication technologies (ICT), digitalization, and automation. Digital transformation and digitalization provide greater access to previously inaccessible knowledge sources and models for their use in the production process and in the organization and management of human resource. It is increasingly evident that the global pandemic has become an accelerant for a number of processes that had already started but were moving too slowly and contradictorily and were showing poor results, such as digitization, automation, technological transformation, and the adoption of innovative and non-traditional business practices. The same is also entering the management processes, helping to organize human resource efficiently, ensure a normal working environment, safety at work, protect the health and lives of employees, and continue the work process despite the constraints of the new normal.

The crisis has thus become a catalyst for the development and deepening of the processes of search for new approaches and models in economics and governance. Traditional models and approaches have lost some of their effectiveness and applicability in the current stage of economic development and crisis context. In a highly competitive and turbulent business environment, the implementation of new approaches and practices is imperative to sustain financial and economic performance and gain competitive advantages [5]. This is particularly true for the current pandemic crisis, as change has long been considered one of the most effective strategic responses to crises [13]. 
However, in times of crisis, they can be difficult and cause additional disruption because quick and decisive action is required, often carried out with limited resources and with very limited response time [6].

The crisis has encouraged collaboration between industrial enterprises from different fields of activity and operating in different countries and geographical regions to seek new and more appropriate business models. Solutions are sought for problems in finance, production, logistics, sales, and human resource management. The pandemic situation, which was unexpected and unplanned, accelerated a number of technological, social, and economic processes. Unplanned investments have been made to accelerate and penetrate digitalization, the development and implementation of telework platforms, remote access to information, information sharing, video conferences, and online communication between employees and managers. Even before the crisis, the intensification of these processes and visible progress in these areas were the focus of effective management in industrial enterprises, but the crisis has given them a significant boost, as evidenced by the intensification of these processes and visible progress in these areas. Changes are inevitable, and the solutions already in place will not be temporary and last only until the crisis situation is over. Some of the process improvement changes will be maintained because they show efficiency and results and are well received by employees, as evidenced by the survey. In a short period of time, the investments of industrial enterprises in the fields of communications, online services, and digitalization have grown exponentially. In parallel, there is an increased demand for collaboration and openness to different alternative solutions to optimize the operations.

In 2021, the global health crisis continued to be a major factor determining the economic activity of industrial enterprises. The uncertainties and unpredictability during the course of the pandemic and the crisis that accompanies it remain significant and strongly tied to countries' vaccination plans and their timely implementation, together with the occurrences and spread of new strains of the virus. The long duration of the measures and their dynamics of tightening and loosening, without the possibility of periods of adjustment, combined with the strength, intensity, and scope of the negative effects, mean that the global, European, and national economies will not be able to go through a rapid economic $\mathrm{V}$-shaped recovery. The recovery is expected to be relatively slower, outpacing in some economic sectors and lagging in others. It will be more K-shaped, with some sectors recovering quickly and even accelerating their development, while others will recover slowly or will not be able to start to overcome the crisis at all until the pandemic situation is over.

All economic actors are affected by the pandemic crisis, albeit unevenly in terms of severity and degree of impact. The current year, 2021, like the previous one, is marked by environmental uncertainty and business risks. The adverse economic effects of the COVID crisis on the Bulgarian economy, insufficient progress in digitalization, digital transformation, process automation, and e-governance have all led to a contraction of the Bulgarian economy and remaining in a waiting mode.

It is expected that countries with stable and efficient health systems, where vaccination rates are relatively higher, will also achieve a faster economic recovery compared to those where vaccination rates are slow with highly contradictory trends of peaks and troughs, including Bulgaria. The uncertain business environment and anti-epidemic measures continue to hold back consumption and investment for a longer than expected period. For the period 2021 2022, international organizations share the view that the recovery in economic activity will be rather slow. The risks for recovery would arise if the virus could not be effectively contained globally in a timely manner, despite the availability of vaccines, and if anti-epidemic measures were extended beyond 2022. There are also uncertainties related to the political cycle in the country, which could be reflected by a postponement of investment spending by enterprises and a halt in development. Another risk that could lead to a weaker recovery of economic activity in the country is the possible delay in the implementation of investment and innovation projects co-financed with EU or national funds.

The outlined trends are indicative of the current situation as a basic starting point for future attitudes in the economy as a development horizon. These trends should be accepted with certain qualifications, as abrupt and unpredictable changes do not allow for much realism and objectivity in the forecast. Nonetheless, it would not be an exaggeration to say that the objective circumstances and course of the crisis draw a very serious and unfavorable picture for economic development and industrial business development. The negative economic effects are significantly larger and more far-reaching than those recorded in relation to the global financial and economic crisis, and thus require different solutions and business responses to be sought and implemented in the short term. This means that it is imperative to seek approaches to overcome the shocks, obstacles, and constraints facing industrial enterprises, as well as new approaches to human resource management.

\section{Strategic crisis management and organizational development}

Strategic human resource management is emerging as a leading direction given the relationship between human resource management, enterprise performance, and financial and economic results. It is associated with the development and implementation of the long-term strategy of the enterprise, as well as the creation and implementation of functional strategies aimed at achieving long-term goals. In this regard, strategic management in times of crisis remains the most problematic and controversial. Human resource management theory interweaves strategic and coherent perspective approaches to human resource management, taking into account the regularities of human potential management, which are seen as an important competitive advantage.

The literature reveals different strategic approaches to human resource management in the industrial enterprise. They are distinguished from each other by the emphasis they place on making an important contribution towards 
realizing the company's objectives and improving its performance. One of these is the integrative approach, which brings together in a common model the main emphases of different approaches, including the contextual, configurational, correspondence, and universal approaches [9].

The integrative approach to strategic human resource management (Figure 1) assumes that for management to be effective, it must include impacts at three hierarchical levels:

- At the level of the individual, focus is not only on individual performance, but also on satisfaction, commitment, and willingness to join and follow the company culture;

- At the organizational level, human resource management policies and practices affect team cohesion and adaptability, the adoption of new technologies, and decision-having directly impacts business performance;

- At the societal level, policies and practices have an effect on the efficient use of public goods, the quality of life of local communities, and the development of human capital [9].
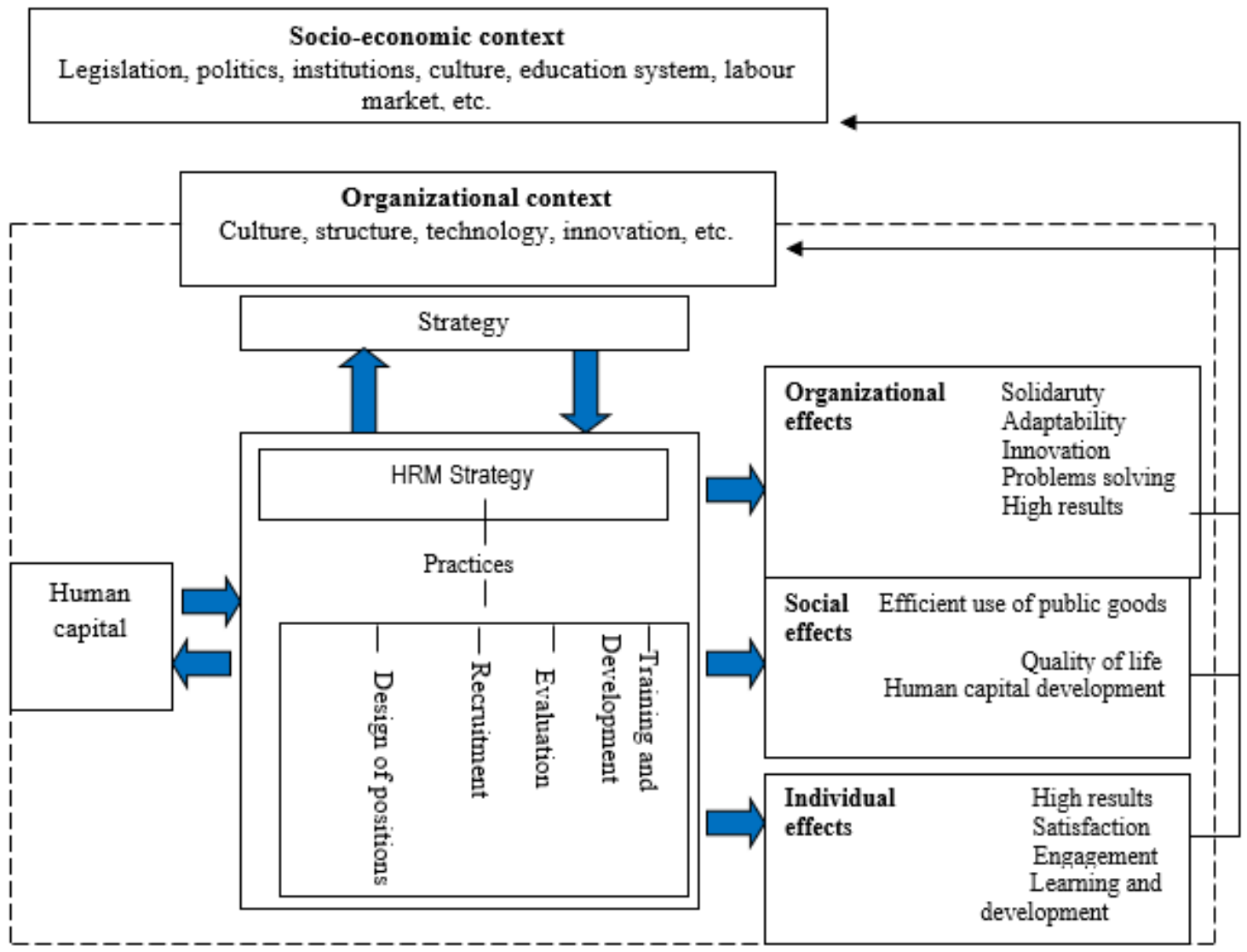

Figure 1. An integrative approach to strategic human resource management

Source: Martin-Alcazar, F., Romero-Fernandez, P., G. Sanchez Gardey. Strategic human resource management: integrating the universalistic, contingent, configurational and contextual perspectives. The International Journal of Human Resourse Management, 16 (5), 2005, p. 65.

The actual practice of strategic human resource management requires that it be considered in the context of the specific situation or crisis, i.e., to be highly adaptive. Such adaptability and flexibility, much needed in the current circumstances, is possessed by the sustainable human resource management model [8]. Based on the integrative approach of Martin-Alcazar [9], Ehnert develops a model for sustainable human resource management focusing on the company's ability to maintain and develop its human resource base [2]. It recommends four potentially feasible strategies:

- Development of resource sources: investment in training and human resource development, in the search for work-life balance and in adequate education;

- Control of the external environment on human resource and sources of resources: investment in safe working conditions and a healthy working environment;

- Maintaining a relationship of mutual exchange of resources: actions aimed at creating a relationship of loyalty and trust with staff and sources of staff;

- Maintaining social legitimacy: includes socially responsible practices that create a favorable company image. 
In the context of the crisis, businesses should demonstrate their responsibility to all of the stakeholders - partners, customers, and employees - by developing appropriate HR policies and strategies. They should be based on the principles of commitment, trust, mutual understanding, and cooperation. Change management processes are of strategic importance. At the forefront is the need to comply with the new social and business realities and to accelerate the already started processes of digitalization, technological transformation, and automation. Changes in culture, model, and way of working, as well as reorganization of business processes and a change in the internal communication model are also required. The forms of work organization and the possibilities for reorganization of the work process, such as home working, teleworking, hybrid work, flexible working hours, organization of meals, breaks, and transport to and from the workplace suitable for the pandemic situation, are becoming increasingly relevant. These are specific areas for change that have the potential to normalize the work process and overcome crisis trends and prospects while maintaining operational efficiency and labor productivity.

The current global economic crisis requires a new look at the management of social phenomena in enterprises and their social responsibility. The adaptability and appropriateness of existing models, as well as the creation and use of new entrepreneurial and innovative approaches to human resource management, are important. The use of a knowledge model that systematizes concepts, approaches, and techniques on the relationship between organizational development and human factor optimization is recommended [4]. The intersections of effective strategic and tactical influence for human resource management in implementing organizational change, managing innovation, and activating opportunities for creative thinking and improvement in organizations are sought.

The founder of the concept of organizational development was the German scientist K. Levin, who studied group dynamics and actions of individuals in business organizations. Carrying out research on the behavior of business organizations, he describes graphically the successive steps as a spiral. In his view, it is important to identify the mechanisms that support the process of their adaptation when implementing organizational change. These mechanisms are derived in three directions:

- Opportunities to share management responsibility;

- Motivational mechanisms and their role in improving HR performance;

- Behavior of individuals in groups, and of groups themselves in organizations (group dynamics).

Making a change requires ensuring a balance between the dissatisfaction and frustration of the people in the organization, the vision for its long-term development, its current goals, and the tactics to achieve them. Organizational development is a set of strategies for making changes in the beliefs, mindsets, values, and structures of organizations in order to optimally adapt them to new technologies, markets, and threats from the external environment [4, p. 367].

Organizational development is a complex and multilayered process aimed at achieving better organizational wellbeing and viability. It includes:

- identifying and exploiting opportunities to adapt the organization to the conditions in which it can operate;

- finding alternative options to improve the interaction between its system elements and the entities that interact;

- improving planning, organization, implementation, and control processes;

- performing situational analysis, planning, and implementing measures to improve the organizational environment.

In order to meet these requirements, greater attention needs to be paid to the skills and capabilities of the staff. An important point in the implementation of the whole process is the identification and minimization of the circumstances that hinder the organizational development, professional and career growth of human resource in the organization and the effective use of human potential.

French and Bell [4] developed several techniques aimed at organizational development. They are used separately or in combination with each other depending on the specific conditions. The most used of them are the following:

- Determining human resource behavior;

- Building a team;

- Creating feedback;

- Education and instruction;

- Group interactions;

- Behavioral structuring through technology;

- Consulting on processes;

- Life and career planning;

- Coach and lawyer;

- Planning and goal setting [4].

To solve some problems in a business organization, the Behavior Diagnosis technique employs methods of analysis and synthesis. After an investigation and a diagnosis of the problems, an analysis is made of the causes leading to the current organizational state. The application of this technique requires the use of correct, reliable, and up-to-date analytical information. Its recruitment involved conducting interviews, developing questionnaires, organizing thematic 
discussions and meetings, and using archival and statistical data. In processing the information, scientific methods adapted to the objectives of the specific process and situation are used to correctly determine the profile of the organization and the situation in which it finds itself.

The Team Building technique is aimed at achieving greater individual effectiveness in the work of each team member. The goal is to improve the bottom line of the business organization by improving the performance and contributions of each member. Successful implementation of the technique requires improvements in human resource management, organizational culture, and analysis of current organizational behavior. Company leaders need to keep in mind that emotions play an essential role [10].

In today's dynamic business environment, the achievement of organizational development goals is related to the introduction of ubiquitous regulatory controls and the development of adequate systems for giving and receiving feedback. The goal is to achieve consistency between the planned and actual results of each organization and to build systematic self-control and self-discipline in each team member.

In a period of imperative structural, organizational, production, and technological change, feedback is required as a mandatory element of the management control function. It provides valuable analytical information on the attitudes of human resource towards the change objectives, the tools for their implementation, and the expected results. This information is necessary for management decision-making and for taking concrete steps towards change.

Education is a specific technique of organizational development that increases the sensitivity of staff to the processes that take place in the organization. Training programs are developed and implemented in enterprises, orienting them not only to the practical performance of tasks but also to the psychological and social receptivity of activities. The goal is to change and rethink human resources' attitudes towards change and innovation, so they can accept and support the implementation of those innovations. Because of the training and additional qualifications, resistance to the planned and implemented changes has been significantly reduced and the objectives have been achieved.

The Group interactions, Behavioral structuring through technology, Consulting on processes, Life and career Planning, Coach and lawyer, Planning and goal setting focus on coordinating individual behaviors through HR's membership in formal and informal groups, mutual support, and information sharing. Membership in the group is related to the interdependence of each member in achieving his personal goals or satisfying his needs. Group interactions as a technique plays an important role in promoting, accepting, and implementing change in a business organization. When the team is influenced by the group, they are more likely to adjust and adapt their individual behavior in the right direction.

\section{Guidelines for using organizational development techniques in practice}

For the practical application of organizational development techniques, no single mechanism that can apply to all situations in business organizations has been developed. The successful application of the techniques depends on the experience, knowledge, skills, and creativity of managers to reconcile the scientific principles with the specific characteristics of the internal and external environment. Depending on the specific situation, managers may decide to use the services of consultants and experts. The presence of weaknesses and deficits in the internal environment, as well as dangers and threats from the external environment, is a signal of the need for change. A key factor for the success of management in such a situation is the identification of the point at which the organization is in a zone of decline and regression and, accordingly, taking quick and adequate action to achieve a positive turnaround. This is how you get a reboot in organizational development.

The main responsibility for making the changes lies with the managers, but despite their experience and qualifications, they are not able to handle every situation adequately. It is therefore necessary to resort to the help of staff or consultants external to the organization. It is recommended that appropriate management and behavioral approaches be used to involve HR in change processes, sharing responsibility for implementing change between staff and managers.

In practice, eclectic models are often applied to make organizational change. They combine the best elements from different models in order to facilitate the change. An important point in implementing changes is to clarify and agree with the groups and units in the organization so that there is clarity about what is being done and why it will be done. The aim is to reach agreements in principle on the type of activities and how to implement them. The envisaged social impact would contribute to the effective implementation of the changes. Psychological impact is a key at each stage of the model, as follows:

- implementation of planned activities concerning the restructuring and reorganisation of the organizational human resource;

- carrying out organizational, structural, and technological restructuring activities;

- implementing tools to improve HR's attitude towards change and its outcomes;

- implementing a strategy to balance the elements of the internal and external environment.

Essential in bringing positive change is management's ability to persuade and influence staff behavior so that it benefits organisational development. Therefore, during the period of analysis, planning, and discussion of the changes, the management of the enterprise should provide the staff representatives with a reorganisation plan and the content of the planned changes. 
1. Involving and contributing to the planning, organization, and implementation of change is an approach that ensures successful implementation. The focus is on building a human resource management system that monitors the opinions and attitudes of the staff and assesses the effectiveness of the motivation policy, institutionalization and socialization of the employees. This will identify and analyse the causes of dissatisfaction and frustration of different team members in a timely manner and allow them to adopt adequate measures to reduce the social tensions and resistance to organisational change. The application of this approach is a form of prevention for any organization against the occurrence of unforeseen circumstances that prevent its timely adaptation to the current conditions of the external environment.

\section{Best practices for strategic crisis management in raw materials companies}

The first question is aimed at identifying the attitudes and opinions formed about the challenges resulting from the co-dependent situation. The attitudes and opinions of the business representatives are very positive and the assessments of the achievements are positive. It should be stressed that this is a self-assessment of performance, so it may not be based only on objective but also on subjective (personal) criteria. The results presented in Figure 2 allow valuable conclusions to be drawn.

Firstly, no respondent indicated that the enterprise had dealt with the crisis and its effects worse or much worse than expected, i.e. planned. This testifies to the rather positive attitudes towards the crisis and its mixed impacts. The assessment of coping is positive and varies within the range of the other two possible responses, which have the same distribution. $50 \%$ of the respondents indicated that they did much better than expected, and the remaining 50\% confirmed that they did better than expected.

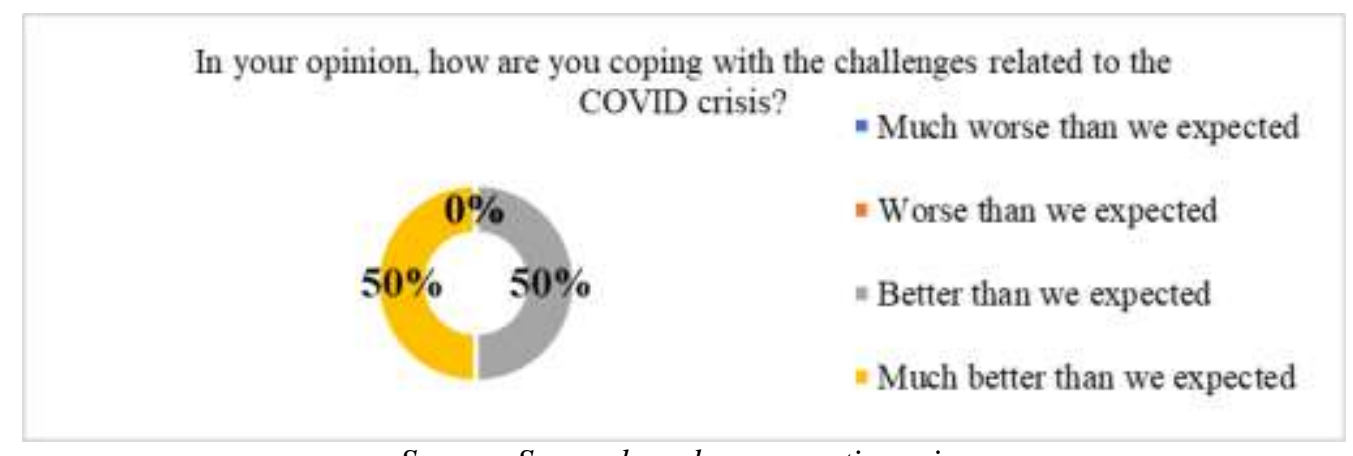

Source: Survey based on a questionnaire

Figure 2. Question: "In your opinion, how are you coping with the challenges related to the COVID crisis?"

Second, it must be concluded that the severity of the crisis and its impact on business have not been underestimated by any of the enterprises. The conclusion is that expectations were for significant and profound shocks at various levels and serious challenges. In all likelihood, the changes made have contributed to addressing them and to establishing relative stability in relation to the dynamics of the external environment. Negative expectations have led to serious measures being taken, and hence problems and challenges have been overcome relatively more easily, which has become the basis for many positive responses. In this sense, the question of what changes have been made to arrive at such a generally valid positive assessment requires further investigation.

The next question is aimed at identifying the hierarchical level at which feedback and information are monitored and provided on the management experience gained so far in the context of the co-dependency crisis, and the need to address its consequences. Before analyzing the results, and for the sake of objectivity, it should be stressed that the respondents indicated all valid answers for their enterprise. In answering this question, it is assumed that they can give more than one answer. For this reason, the overall result exceeds $100 \%$, as all respondents indicated two or more response options that were correct for their business practice (Figure 3). 


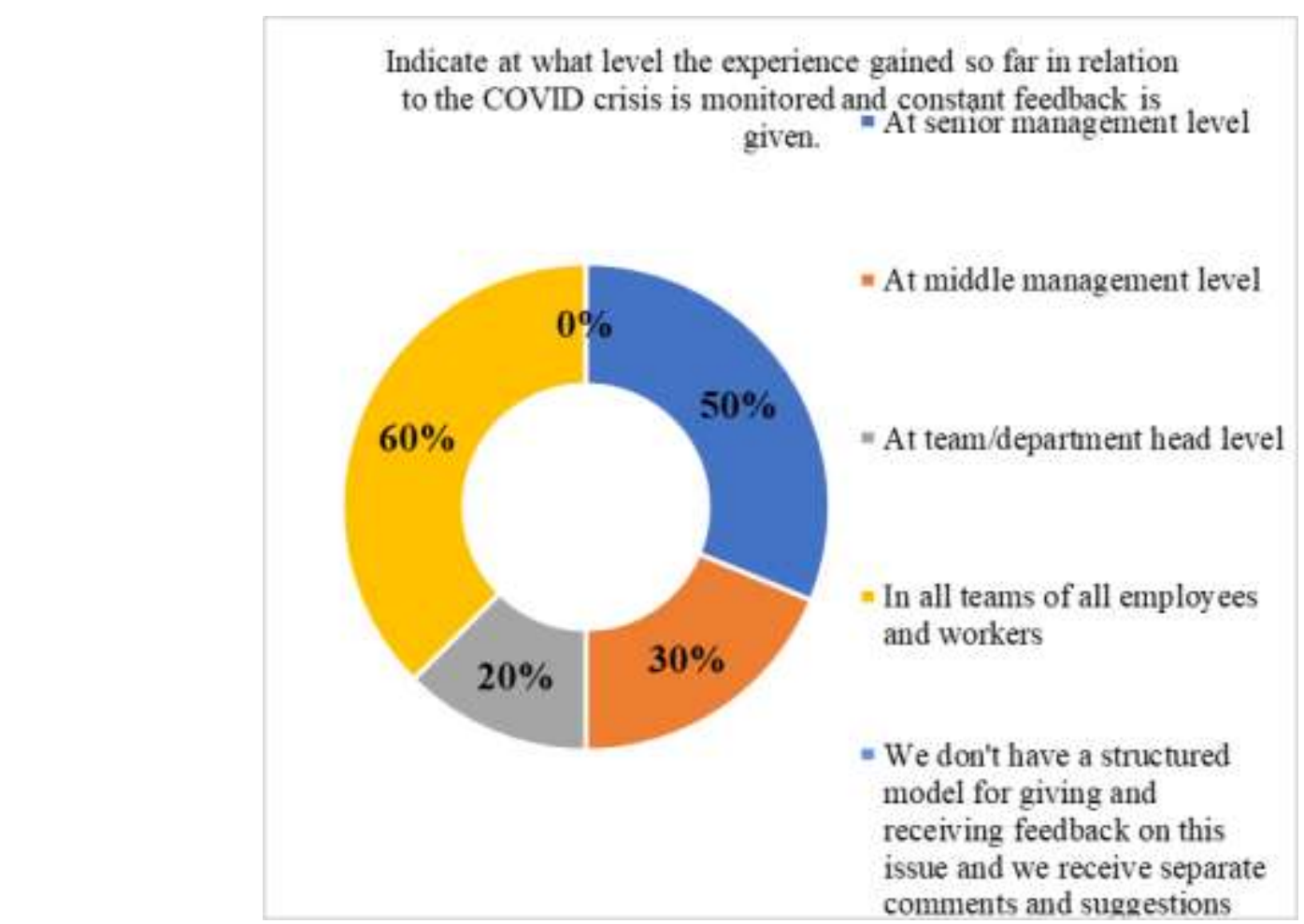

Figure 3. Question: "Indicate at what level the experience gained so far in relation to the COVID crisis is monitored and constant feedback is given."

Source: Survey based on a questionnaire

As can be observed from the graphical representation of the results, the vast majority of respondents indicated that this is done at the senior management and middle management levels (80\% overall). Only $20 \%$ indicated that the communication in question takes place at the level of team leaders or departments, and $60 \%$ said that this process happens in all teams of all employees and workers.

From these results, a significant and intensive exchange of information can be identified, which contributes to the accumulation of experience and its exchange in relation to changes in human resource management strategies, policies, and approaches. This is particularly important for exploring good and effective practices and weeding out those that are not working and have not been well received by staff. These generalizations provide a foundation on which new human resource management strategies and policies can be built. 


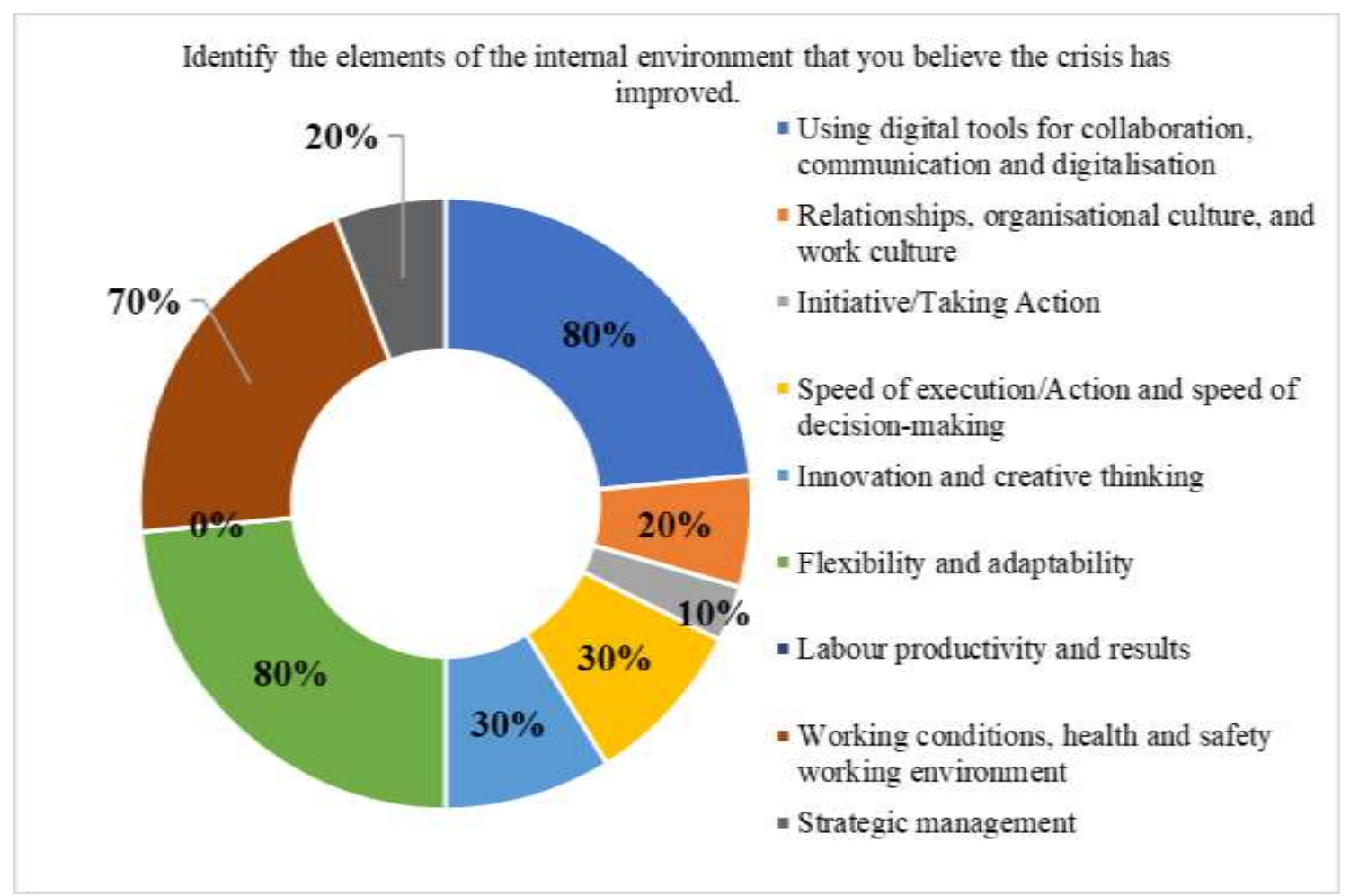

Source: Survey based on a questionnaire

Figure 4. Identify the elements of the internal environment that you believe the crisis has improved.

The next question is aimed at tracking those elements of the internal environment that, according to the respondents' assessment, have undergone improvements as a result of the occurrence of the cover situation. A basic assumption is that each respondent is entitled to indicate all the proposed answers that they consider valid for the enterprise they represent. All respondents indicated more than one answer, and therefore the results obtained exceed $100 \%$.

The main idea of the question is to track which of the possible response options gathered the highest share and were therefore rated as the most positively influenced. Eighty percent of all respondents indicated that digitalisation and its corresponding processes were the elements of the internal (organisational) environment that were most affected. Consequently, digital tools for collaboration and communication within and across teams are increasingly being used, and digital solutions to emerging challenges in the organization and management are being mandated.

Digitalization is a leading trend in the context of Industry 4. 0 and its penetration into enterprise systems and processes started long before the kow crisis. However, it can be argued that the penetration rate was unsatisfactory, as evidenced by numerous studies at national level. Compared to the European average, there will also be a number of weaknesses in the area and a lag behind the expected level. These answers provide a basis to confirm the hypothesis that the co-opetition crisis has been a key factor in accelerating digitalization processes in extractive industry companies that have turned to them to cope with new realities and demands.

Flexibility and adaptability are listed next. Obviously, these are important signs and success criteria for industrial enterprises. Eighty percent of respondents indicated that enterprises have focused on increasing their adaptability and flexibility. This is a logical response to the great dynamism and uncertainty, the exacerbated risks and increased uncertainty of the external environment, including economic and social ones, and to changes in the requirements for the organisation of work processes and production. Apparently, business representatives believe that increased flexibility is both a tool to overcome the crisis and a result of circumstances. That is, it is both a consequence and a prerequisite.

Working conditions and improving the working climate by ensuring healthy and safe working conditions were ranked third most frequently with $70 \%$. This response logically achieves great approval because of the crisis that has occurred, which further exacerbates the need to ensure a healthy working environment and to comply with all the requirements and regulations introduced by the anti-epidemic measures at national level. The high proportion of respondents indicating this answer shows that the vast majority of businesses recognise the importance of the working environment, microclimate, safety and risk mitigation as key factors in business performance. This is logical, because in an uncertain environment, it is important to first ensure the peace of mind and health of employees, so that this can be the basis for a normal workflow and continuity of the production process. 
The two most frequent responses were two: first, innovation and creative thinking; and second, speed of execution or action and speed of decision making, at 30\% each. In a time of crisis affecting various aspects of economic and social life, innovation and a creative approach to business problems are a logical factor for overcoming them. The need for innovative and unconventional approaches, for a new type of thinking and action, which has not been typical or adopted before, has been recognised. There is an acute need to implement different approaches that are more flexible and nonlinear because the current ones cannot meet the new requirements for workflow organization.

It can be assumed that the speed of execution and action, as well as the speed of decision and decision making, have become higher because the dynamics of the environment in a COVID situation do not tolerate waiting, long deliberation, and serious time lag. Some management decisions have to be made in a short time without undergoing extensive analysis and without having many options to choose from. The reason for this is the new standards, requirements, and opportunities that are imposed both formally and objectively and subjectively, due to the changing attitudes and expectations of employees themselves. In practice, this means that the strategy, policies, and tools that will be used to manage human resource will also undergo some changes.

Relationships, organizational culture, and work culture were the responses that garnered 20\% approval from respondents. Despite the modest result, a small minority of participants also noticed positive changes in these important elements of the organizational environment.

It is noteworthy that strategic management only reaches $20 \%$ approval. This fact raises certain questions and unknowns. On the one hand, strategic management is fundamental to crisis management of human resource, which has been demonstrated by both theory and good practice. On the other hand, the responses indicate that improvement in strategic management as an element of organizational structure is not being reported. This suggests that more attention should be paid to the strategic planning and management process going forward.

The next question focuses on the elements of the corporate environment that the crisis has worsened. Are there any elements that are deteriorating, and if so, which ones? Employee relations, organizational and work culture stand out with the highest share $(60 \%)$. These results are worrying, given that relationships and the culture and way of working that are enforced are a key factor in effectiveness and efficiency. At the same time, the outcome is not surprising and is to be expected, as during a pandemic there is a lack of opportunities for meetings in person between team members and different teams and in a traditional working environment, discussing important work issues. In any case, this exacerbates the need for more and better quality and regular communication, removing communication noise and changing traditional approaches and channels of communication.

It can be argued that the crisis is a prerequisite for the deterioration of communication and a reduction in its frequency and intensity. On the other hand, communication is mainly taking place in a digital environment through the use of modern advances in technique and technology. This creates good conditions for communication, but it is clear from the responses that the results of this communication are not good enough. In this sense, it is advisable not to rely solely on online communication but to have periodic meetings and live operations in a safe environment and in compliance with the requirements and regulations related to the species restrictions, whenever possible. A combination of online communication and face-to-face meetings would contribute to addressing the deficits recorded.

The frequency of this communication is also important, and all other things being equal, less frequency makes teamwork worse and vice versa. The reason for this is that irregular communication does not allow for discussion, the exchange of ideas, and solutions to problems. In team tasks, active communication and a proactive stance by the leader, combined with initiative by team members, yield a good level of efficiency and results.

At the same time, $30 \%$ of the respondents indicated that the COVID pandemic had negatively affected the speed with which tasks were completed. This result is logical given that some staff, in particular those in administrative positions, work remotely or in hybrid mode. This could, in all likelihood, lead precisely to delays in certain administrative and organizational issues. Combined with delayed and intermittent communication and difficulty connecting employees, speed can be reduced. Difficulties also arise when working in teams in which some members work at their workplace and others are online or in hybrid mode. This has a negative impact, especially on the administrative and organizational activities of the enterprise.

To increase the speed, it may be advisable to find the right approach by combining the possible options and finding a working one for the respective enterprise. It is logical and reasonable to analyze the results in terms of the speed achieved in carrying out activities and tasks and to identify the causes of delays. If they are removed and a suitable formula is found to adapt the processes, the speed will be increased.

Strategic management, labor productivity and results, initiative and action orientation collect $10 \%$ each. This means that the respondents do not think that labor productivity has decreased as a result of the COVID crisis, which is a particularly positive fact. The hypothesis that the performance has deteriorated due to the specific situation is not confirmed. This trend is favorable because it confirms that companies have managed to find the right approach and maintain the achieved level in terms of labor productivity. 


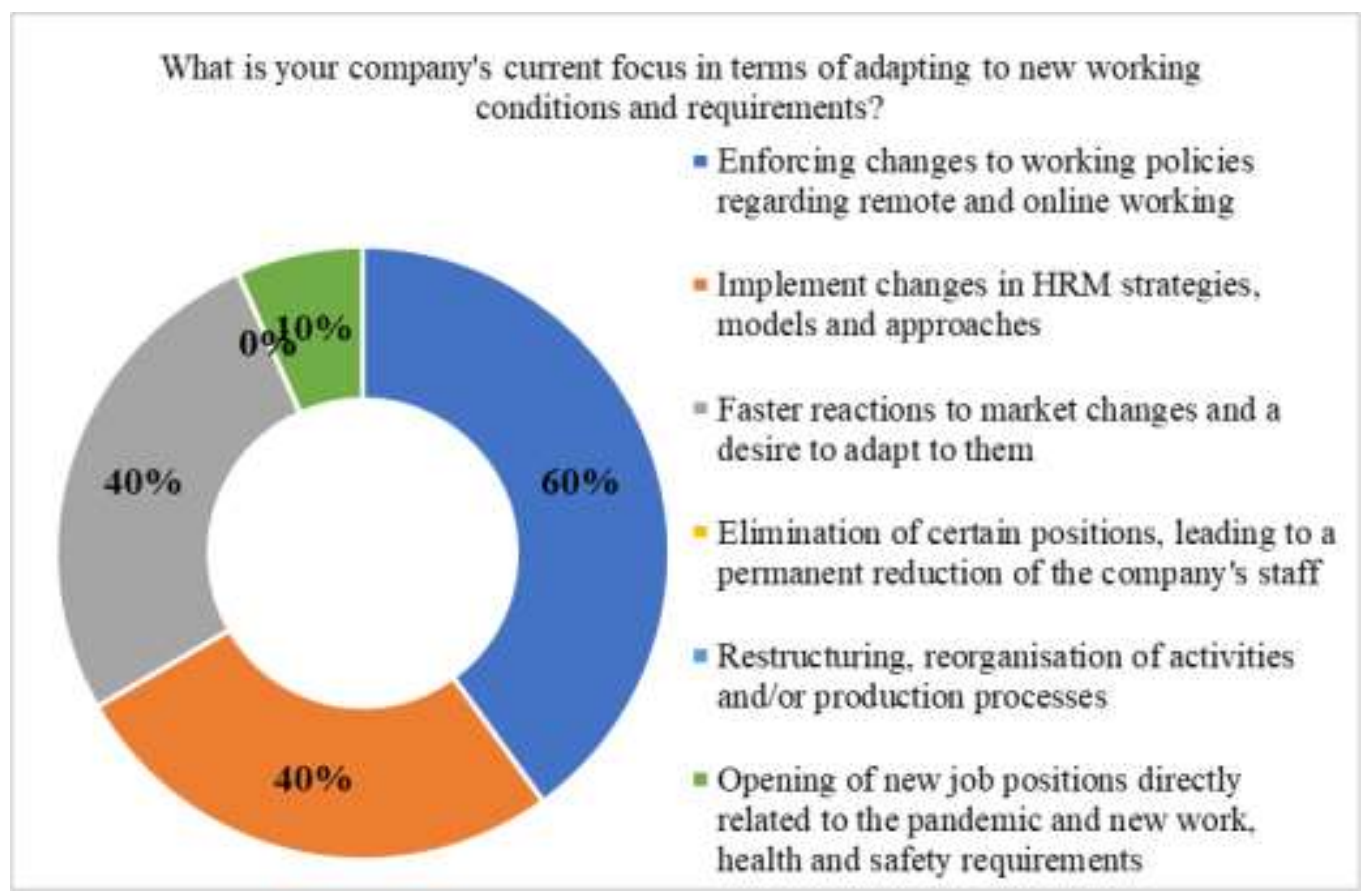

Source: Survey based on a questionnaire

Figure 5. Question: "What is your company's current focus in terms of adapting to new working conditions and requirements?"

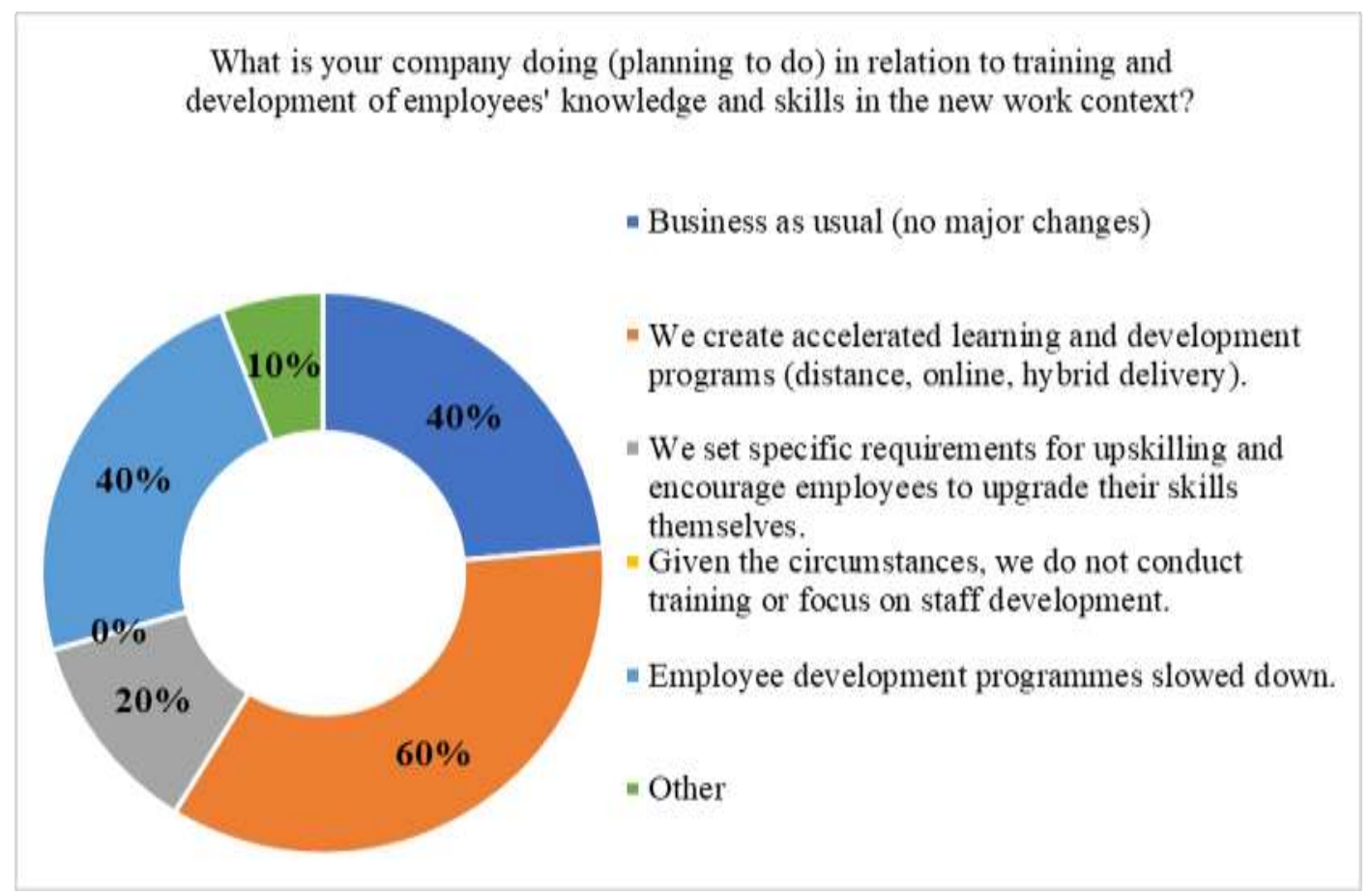

Source: Survey based on a questionnaire

Figure 6. Question: "What is your company doing (planning to do) in relation to training and development of employees' knowledge and skills in the new work context?"

Another important issue that shows different aspects of the topic of strategies and policies is the current approaches to staff training and the acquisition of new knowledge and skills. They become even more important in the new work context to which we have to adapt. The basic assumption is that each respondent has the right to indicate all the proposed answers that he considers valid for the company he represents. For this reason, all respondents indicated more than one answer, and the results exceeded $100 \%$. 
It is important to monitor whether companies have stopped the internal process of training and building skills in staff by conducting various courses, seminars, discussions, and certification programs. Sixty percent of respondents say that during the COVID pandemic, they developed new training programs or adapted old ones to meet the new realities. The form of the training was flexible, offering training and courses online, in a hybrid form, or on the job, with such a practical opportunity.

Therefore, in most of the surveyed companies, the training process was not terminated, and the crisis did not have a negative impact. In these $60 \%$, the processes not only didn't stop, but have been accelerated due to the need to adapt to the new environment. Trainings were conducted for the development of digital skills, communication in the online environment, working with programs and platforms for communication, or new software products.

Twenty percent of the respondents focused on encouraging employees to improve their knowledge and skills on their own, as work processes in a new environment require it. None of the respondents indicated that the staff training and development programs were terminated or suspended due to the circumstances. This fact shows that companies are aware of the need to continue training, and even accelerate it, because they recognize the need to develop new skills, overcome the challenges of online communication, and work with new software products. It is estimated that $40 \%$ still state that the COVID crisis has led to some delays in employee development programs, but they have not been stopped altogether.

Figure 6 presents the expectations for the approaches of human resource managers in the coming years. Again, it is acceptable to indicate more than one valid answer, so the distribution significantly exceeds $100 \%$. When asked, $80 \%$ of respondents said that in the future they expect a hybrid approach to work and management - online and live - as well as a move to a flexible organizational structure. Fifty percent of the respondents expect the application of agile methodology to be expanded.

It was found that $40 \%$ define as a future approach the change in organizational culture and way of thinking and the acquisition of additional qualifications to increase the skills and competencies of employees through online training and distance learning. It is noteworthy, that despite the digitalization of the raw materials industry, in the context of human resource, managers do not envisage a focus on high technology, including the use of artificial intelligence, virtual reality, blockchain, robotics, and automation in the field of human resource.

As it can be seen, the prevailing opinion is that hybrid work will be a possible approach where it is practically possible (mainly in administrative activities and much more limited in production). Most (80\%) of the respondents expect that the hybrid way of working and the mixed approach to leadership — live and online - and the introduction of greater flexibility in the organizational structure will be necessary and will remain more lasting in the coming years. It can be stated that these are changes that were necessarily introduced in a very short time and were caused mainly by the pandemic and the limitations of the work process that it imposes. However, managers recognize in them innovative practices that have the potential to find a place for a longer time. However, 50\% recognize the role of flexible methodologies and agile methods in the human resource management process. Before the pandemic, they were also less common and difficult to use in strict organizational structures (linear and functional).

It can be summarized that several main directions prevail in the changes made: digitalization of processes; use of technology opportunities and technological progress for the purposes of human resource management and maintenance of communication and production processes; switch to hybrid or online mode; transition to flexible models in the accounting and distribution of working time; creation of training and development programs for staff based on the use of online communication platforms and modern software products.

It can be summarized that several basic skills and competencies predominate, namely: flexibility, adaptability, ability and orientation to change; ability to engage the team in remote working conditions; ability to create a good working micro-climate based on trust, exchange of ideas, empathy, activity, and initiative.

It is noteworthy that all these answers tend, in particular, to personal skills and competencies, and not so much to strictly professional and specialized ones. Therefore, according to the respondents, it is of great importance to develop soft and communicative skills and competencies that will help to manage, lead, motivate, and encourage work teams that need to take into account the new work reality. Emphasis is placed on the importance of the process of communication within the team and between teams so that the work process can continue successfully according to the new rules of the COVID and post-COVID era.

\section{Conclusion}

As a result of the study, the expectations of the raw materials enterprises regarding the challenges related to the COVID crisis were for significant and deep shocks at various levels and serious problems. In all likelihood, the changes made have contributed to dealing with them and to establishing relative stability in relation to the dynamics of the external environment. Negative expectations have led to serious measures: digitalization of processes, use of technological opportunities and technological progress for the purposes of human resource management and maintenance of communication and production processes; switching to hybrid or online mode; transition to flexible models in the accounting and allocation of working time. In the internal environment of these enterprises, a significant and intensive exchange of information has been found, which contributes to the accumulation of experience and its exchange in connection with changes in strategies, policies, and approaches in human resource management. This is 
especially important for researching good and effective practices and pointing out those that are not working or have not been well received by the staff. These summaries are the foundation on which the new strategies and policies for human resource management are built in these enterprises.

There is a need for retraining and acquiring more digital skills, which are essential in today's business practice, and reformulating the organizational culture. The attitude towards a change in the organizational culture can be interpreted as a positive, which is a prerequisite for any further changes. It is noteworthy that it is not approved the use of new technologies such as the Internet of Things, artificial intelligence, blockchain, and virtual reality. The application of information technologies leads to the improvement of the companies' production parameters in each sector according to the criteria for sustainable development [11]. It is obvious that automation and digitalization are still not fully recognized as an opportunity to improve human resource management processes and overcome the difficulties that have arisen in the ways and approaches to work so far. These results show that managers are focused on changes in different directions, adapting models, approaches, and structures. At the same time, they remain more conservative about the opportunities offered by digitalization and high technology in human resource management. This conclusion raises many questions: why are managers not open to these options and what are the reasons for this, especially in the context of the emerging direction of "Industry 4.0"? These issues should be the subject of further research, as the search for causes and the tracking of attitudes are at the heart of clarifying the current situation and prospects for development.

\section{References}

1. Велчев. В. Криза в предприятието: фази, фактори и подходи за изследване. //Известия 2/2012, Специално издание „Икономически, социални и екологични предизвикателства пред регионалната и национална конкурентоспособност. Наука и икономика, Варна, 2012, с. 89-101.

2. Данкова, П. Стратегически аспекти на управлението на човешките ресурси в бизнес организацията. //Сп. „Известия на ИУ-Варна”, бр. 1/2012, с. 62-73.

3. Петранов, С. и др. (2020). Икономически последствия от кризата с COVID-19 и мерки за предотвратяването им, (онлайн ресурс), 2020, https://www.uni-sofia.bg, (date of access 1.10.2020)

4. Радев, К. Управление на човешките ресурси. Сборник под редакцията на Д. Панайотов, Глава 7. НБУ, 2012, c. $365-409$.

5. Baregheh, A. Rowley, J., S. Sambrook. Towards a multidisciplinary definition of innovation. //Management Decision, 2009, Vol. 47, No. 8, p. 1323-1339, https://doi.org/10.1108/00251740910984578

6. Chesbrough, H. To recover faster from Covid-19, open up: Managerial implications from an open innovation perspective. Industrial Marketing, Volume 88, July, 2020, p. 410-413.

7. Gevorkyan, A. Economic Crisis, Wiley Encyclopedia of Management, Volume 6. International Management, 2015, https://doi.org/10.1002/9781118785317.weom060061

8. Ehnert, I. Sustainable Human Resource Management: A Conceptual and Exploratory Analysis from a Paradox Perspective, Physica-Verlag Berlin/ Heidelberg, 2009.

9. Martin-Alcazar, F., Romero-Fernandez, P., G. Sanchez Gardey. Strategic human resource management: integrating the universalistic, contingent, configurational and contextual perspectives. The International Journal of Human Resourse Management, 16 (5), 2005.

10. Mura, L., Zsigmond, T., R. Machová. The effects of emotional intelligence and ethics of SME employees on knowledge sharing in Central-European countries. Oeconomia Copernicana, 12(4), 2021, p. 907-934. https://doi.org/10.24136/oc.2021.030

11. Hristova, T., Anastasov, D., Evtimov, Z. Defining the information flows for DLT of a transport company in the mining industry according to the criteria for sustainable development, E3S Web Conf. Volume 280, 2021, Second International Conference on Sustainable Futures: Environmental, Technological, Social and Economic Matters (ICSF 2021), Sustainable Mining

12. Laing, T. The economic impact of the Coronavirus 2019 (Covid-2019): Implications for the mining industry, The Extractive Industries and Society, Volume 7, Issue 2/2020, p. 580-582, https://doi.org/10.1016/j.exis.2020.04.003

13. Wenzel, M., Stanske, S., M.B. Lieberman. Strategic responses to crisis. Strategic Management, 2020, Vol. 42, Issue 2, p. 8-18.

14. Zsigmond, T. et al. Strategic Management from the Perspective of SMEs Operating in Service Sector. Quality Innovation Prosperity, 25 (2), 2021, p. 37-53, https://doi.org/10.12776/qip.v25i2.1549 